\title{
Nkx2.5 insufficiency leads to atrial electrical remodeling through Wnt signaling in HL-1 cells
}

\author{
JINGJING CHEN ${ }^{1}$, SHUNEN XU ${ }^{2}$, WEI LI ${ }^{1}$, LIRONG WU ${ }^{1}$, LONG WANG ${ }^{1}$, YONGKANG LI $^{1}$ and WEI ZHOU ${ }^{1}$ \\ Departments of ${ }^{1}$ Cardiology and ${ }^{2}$ Orthopedics, The Affiliated Hospital of Guizhou Medical University, \\ Guiyang, Guizhou 550004, P.R. China
}

Received March 15, 2019; Accepted September 26, 2019

DOI: $10.3892 /$ etm.2019.8134

\begin{abstract}
Homeobox protein Nxk-2.5 (Nkx2.5) is a homeobox transcription factor that promotes chamber-like myocardial gene expression. Data from a previous genome-wide association study suggested that $\mathrm{Nkx} 2.5$ may be associated with the genetic variation that underlies atrial fibrillation (AF). $\mathrm{Nkx} 2.5$ loss of function has been demonstrated to be associated with an increasing susceptibility of familial AF. Therefore, the aim of the present study was to investigate the effect of $\mathrm{Nkx} 2.5$ loss of function on electrophysiological substrates in HL-1 cells. To the best of our knowledge, the results demonstrated for the first time that $\mathrm{Nkx} 2.5$ expression was significantly decreased in a rat model exhibiting AF. The effect of silencing Nkx2.5 was assessed following transfection with adenoviral vectors with specific NKX2.5-shRNA. The effect of Nkx2.5 silencing on potassium/sodium hyperpolarization-activated cyclic nucleotide-gated channel 4 (HCN4), gap junction alpha-5 protein (Cx40), calcium handling proteins and protein Wnt-11 (Wnt11) expression levels was also assessed in HL-1 cells. The results revealed that $\mathrm{Nkx} 2.5$ silencing increased $\mathrm{HCN} 4$ expression, decreased $\mathrm{Cx} 40$ expression and disrupted the expression of calcium handling proteins. Additionally, Wnt11 signal protein expression was decreased following $\mathrm{Nkx} 2.5$ silencing. The results of the present study demonstrated that $\mathrm{Nkx} 2.5$ served as a transcriptional regulator of the electrophysiological substrates associated with AF.
\end{abstract}

\section{Introduction}

AF affects $1-2 \%$ of the general population and is the most common type of persistent arrhythmia (1). AF is associated with an increased risk of thromboembolism and heart failure (2)

Correspondence to: Dr Wei Zhou, Department of Cardiology, The Affiliated Hospital of Guizhou Medical University, 28 Guiyi Street, Guiyang, Guizhou 550004, P.R. China

E-mail: zhouwei008235@163.com

Key words: atrial fibrillation, electrical remodeling, homeobox protein Nxk-2.5
Homeobox protein Nxk-2.5 ( $\mathrm{Nkx} 2.5)$ is a homeobox transcription factor that promotes chamber-like myocardial gene expression (3). Loss of Nkx2.5 function has been revealed to promote a pacemaker-like phenotype in the pulmonary vein, which may increase ectopic pacemaker activity. Results from a previous genome-wide association study (GWAS) suggested that $\mathrm{Nkx} 2.5$ may be associated with the genetic variation that underlies AF (4). Additionally, a previous study demonstrated that $\mathrm{Nkx} 2.5$ loss of function was associated with an increased susceptibility to familial AF (5). However, this study did not include an assessment of the association between $\mathrm{Nkx} 2.5$ silencing and atrial electrical remodeling.

The results of the present study demonstrated that $\mathrm{Nkx} 2.5$ mRNA and protein expression levels were decreased in a HF rat model. These data revealed an association between $\mathrm{Nkx} 2.5$ and AF. In addition, the effect of Nkx2.5 silencing on potassium/sodium hyperpolarization-activated cyclic nucleotide-gated channel 4 (HCN4), gap junction alpha-5 protein $(\mathrm{Cx} 40)$, calcium handling proteins and protein Wnt-11 (Wnt11) signal expression levels were assessed in HL-1 cells. Nkx2.5 silencing increased HCN4 expression, decreased Cx40 expression and caused disturbance in the expression of calcium handling proteins. Furthermore, Wnt11 signal protein expression was decreased following Nkx2.5 silencing. These data suggested that $\mathrm{Nkx} 2.5$ is a transcriptional regulator associated with electrophysiological substrates.

\section{Materials and methods}

Animal model of MI. All experimental protocols were approved by The Experimental Animal Care and Institutional Animal Ethical Committee of Guizhou Medical University (Guizhou, China). All experiments performed conformed to The Guide for the Care and Use of Laboratory Animals published by the US National Institutes of Health (NIH publication No. 86-23, revised 1985) (6). A total of 24 Male Sprague-Dawley rats (weight 200-250 g) which were purchased from Hunan Silaike Jingda Laboratory Animal Co., Ltd., (animal license no. 43004700021663). The rats were acclimatized at $25^{\circ} \mathrm{C}$ with a 12 -h light/dark cycle and relative humidity of between 40 and $70 \%$, and had free access to food and water. The rats were anaesthetized with intraperitoneal sodium pentobarbital (40 mg/kg; Sigma Aldrich; Merck $\mathrm{KGaA}$ ). Subsequent to ventilation with oxygen, a thoracotomy 
was performed. The left descending (LAD) coronary artery was ligated with 7-0 silk suture to produce an ischemic area consisting of $40-50 \%$ of the left ventricle. Sham group rats underwent a thoracotomy without ligation of LAD. A total of 4 weeks after surgery, echocardiography was performed to assess left ventricular function. MI group rats with a left ventricular ejection fraction of $>70 \%$ were excluded from the MI group. Rats were sacrificed and the left atrium (LA) tissues were frozen at $-80^{\circ} \mathrm{C}$.

RNA interference. Adenoviral vectors carrying short hairpin RNA (shRNA) that targeted rat Nkx2.5 and green fluorescent protein (GFP) genes were designed and synthesized by Hanheng Biological Technology Co., Ltd. The adenoviral vectors with GFP only and without the knockdown sequence were used as the negative control (NC) group. The sequences of the shRNA-NKX2.5 duplexes were as follows: Sense, 5-CCG GGCCCTTCTCAGTCAAAGACATCTCGAGATGTCTTT GACTGAGAAGGGCTTTTTTG-3 and anti-sense, 5-GAT CCAAAAAAGCCCTTCTCAGTCAAAGACATCTCGAGA TGTCTTTGACTGAGAAGGGC-3'. The adenoviral particles encoding the shRNA-NKX2.5 and negative control were measured as $1 \times 10^{10} \mathrm{PFU} / \mathrm{ml}$ and were preserved at $-80^{\circ} \mathrm{C}$.

Cell culture and NKX2.5 shRNA transfection assays. HL-1 cells are a cardiac cell line from the AT-1 mouse atrial cardiomyocyte tumor lineage that has retained the differentiated cardiac morphological, biochemical and electrophysiological properties of adult atrial myocytes (7), and they have been used previously for the study of atrial myocytes electrophysiology (8). HL-1 cells were used to perform the Nkx2.5 loss of function experiments. HL-1 cells were cultured under appropriate conditions and plated onto 6-well plates. HL-1 cells were transfected with shRNA-Nkx2.5 at different multiplicities of infection (MOI; 0, 5, 10, 15, 20 and 50), to identify the appropriate MOI. Sh-Nkx2.5 were transfected into HL-1 cells using Lipofectamine 2000 (Invitrogen; Thermo Fisher Scientific, Inc.) according to manufacturers protocol. NC HL-1 cells were transfected with adenoviral vectors carrying GFP only. A period of $4 \mathrm{~h}$ subsequent to transfection, HL-1 cells were cultured in a humidified atmosphere of $5 \% \mathrm{CO}_{2}$ at $37^{\circ} \mathrm{C}$ in Claycomb medium (Sigma-Aldrich; Merck KGaA) supplemented with $10 \%$ fetal bovine serum, $2 \mathrm{mM}$ l-glutamine (Invitrogen; Thermo Fisher Scientific) and $0.1 \mathrm{mM}$ norepinephrine (Sigma-Aldrich; Merck KGaA) as previously described (6). Transfection efficiency was assessed using light and fluorescent microscopes (Olympus Corporation) $24 \mathrm{~h}$ after transfection (magnification, x100). A total of $48 \mathrm{~h}$ after transfection, reverse transcription-quantitative polymerase chain reaction (RT-qPCR) and western blot analysis were performed to assess the efficiency of $\mathrm{Nkx} 2.5$ silencing at the mRNA and protein levels, and HL-1 cells were harvested for subsequent experiments.

RT-qPCR analysis. RT-qPCR analysis was performed to assess Nkx2.5, HCN4 and Cx40 mRNA levels present in HL-1 cells and Nkx2.5 expression in the rat LA tissues. Total RNA was extracted from snap-frozen tissues and HL-1 cells using TRIzol ${ }^{\circledR}$ (Thermo Fisher Scientific, Inc.). RNA $(2 \mu \mathrm{g}$ each sample) was subsequently reverse transcribed from
cDNA using a Transcriptor First Strand cDNA Synthesis kit (Cat. No. 11483188001; Roche Diagnostics GmbH) according to the manufacturers protocol. PCR amplification was quantified using SYBR Green Master Mix (Vazyme). The primers sequences were as follows: NKX2.5 forward, 5-ACGCCC TTCTCAGTCAAAGA-3 and reverse, 5-TAAAATGTA GGGGCGGTTGG-3; Cx40 forward, 5-TGGGCCAGTACC TCСТCTAT-3 and reverse, 5-GATCTTCTTCCAGCCCAG GT-3; HCN4 forward, 5-AACCTGGGGGCTGGACAGA-3 and reverse, 5'-CTGGGCAGCCTGTGGAGAG-3'; GAPDH forward, 5'-ACAGCAACAGGGTGGTGGAC-3' and reverse, 5'-TTTGAGGGTGCAGCGAACTT-3'. The expression of the target genes was normalized to that of GAPDH by applying the $2^{-\Delta \Delta \mathrm{Cq}}$ method (9).

Western blot analysis. Western blot analysis was performed to assess the levels of Nkx2.5, HCN4, Cx40, sarcoplasmic reticulum Ca2 ${ }^{+}$-ATPase (SERCA2a), total ryanodine receptor (RyR) and phosphorylated RyR at the serine-2814 site (p2814-RyR), voltage-dependent L-type calcium channel subunit alpha-1C $\left(\mathrm{Ca}_{\mathrm{v}} 1.2\right)$, total phospholamban (PLB), phosphorylated phospholamban at Thr17 (P-PLB) and Wnt11 protein expression in HL-1 cells. A total of 4 weeks after surgery, rat hearts were harvested following euthanasia. The LA tissue was used for detecting Nkx2.5 protein expression. Total HL-1 cell and LA tissue proteins were extracted separately using RIPA lysis buffer (Beyotime Institute of Biotechnology). Protein concentration was examined using a BCA protein assay kit (cat. no., AS1086; Aspen Biological). A total of $40 \mu \mathrm{g}$ protein was separated by $8-12 \%$ SDS-PAGE and transferred onto equilibrated polyvinylidene difluoride (PVDF) membranes. Subsequently, the PVDF membranes were blocked with 5\% skim milk for $1 \mathrm{~h}$ at room temperature and incubated with primary antibodies overnight at $4^{\circ} \mathrm{C}$ against Nkx2.5 (1:1,000; cat. no., ab106923; Abcam), HCN4 (1:1,000; cat. no., ab32675; Abcam), Cx40 (1:1,000; cat. no., ab16585; Abcam), SERCA2a (1:500; cat. no., ab2861; Abcam), ryanodine receptor (RyR; 1:1,000; cat. no., ab2868; Abcam), RyR2 phosphorylated at serine (S)2814 (P2814-RyR2; 1:500; cat. no., A010-31; Badrilla Ltd.), $\mathrm{Ca}_{\mathrm{v}} 1.2$ (1:500; cat. no., ab84814; Abcam), PLB (1:1,000; cat. no., ab85146; Abcam), phosphorylated (p)-PLB (1:500; cat. no., ab62170; Abcam) and Wnt11 (1:1,000; cat. no., ab31962; Abcam). After washing, membranes were subsequently treated with horseradish peroxidase (HRP)-conjugated rabbit anti-goat IgG (1:10,000; cat. no. AS1108; Aspen Biological) or HRP-conjugated goat anti-rabbit IgG (1:10,000; cat. no. AS1107; Aspen Biological) secondary antibodies for $1 \mathrm{~h}$ at room temperature. The chemiluminescence of the blots was detected using an ECL kit (Beyotime Institute of Biotechnology) and protein expression was normalized to GAPDH. Densitometric analysis was subsequently performed using the Image J software (version 15.0; National Institutes of Health).

Statistical analysis. Statistical analysis was performed using SPSS v.19.0 (IBM Corp). Data was expressed as the mean \pm standard error of the mean. Comparisons between the data were performed using an unpaired Students t-test. $\mathrm{P}<0.05$ was considered to indicate a statistically significant difference. 

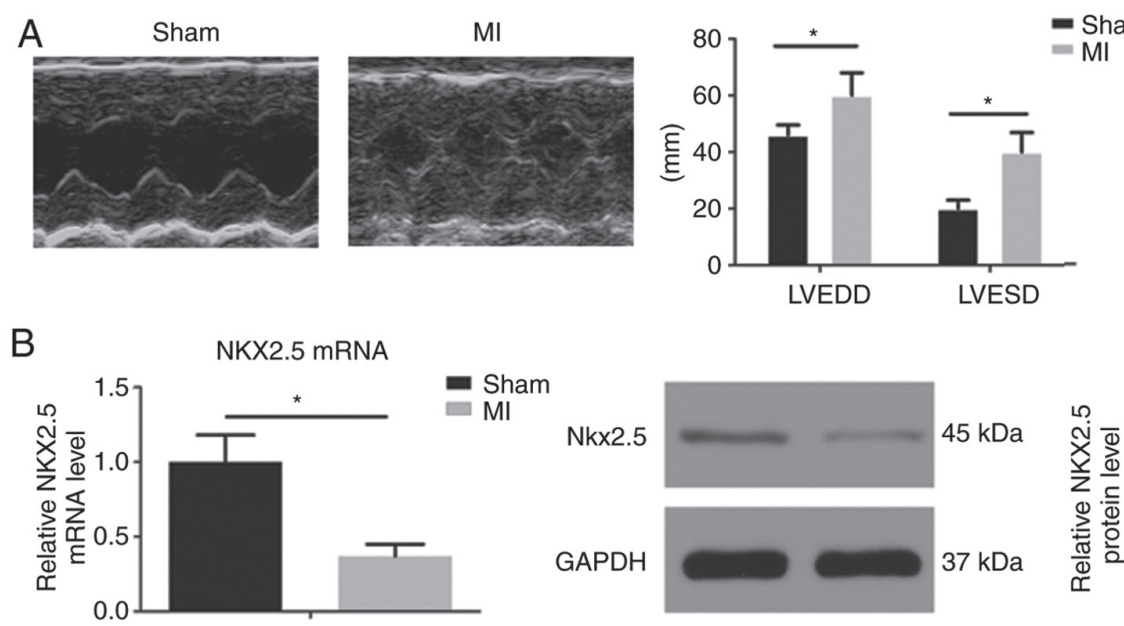

Nkx2.5
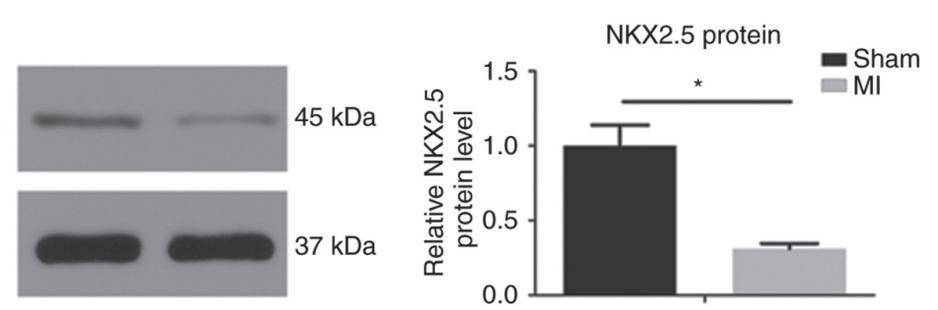

Figure 1. Heart function 4 weeks after myocardial infarction and the mRNA and protein expression levels of Nkx2.5 in the LA of a myocardial infarction-heart failure rat model. (A) Representative echocardiographic images and summary analysis in sham and myocardial infarction groups ( $\mathrm{n}=6$ animals/group). (B) Nkx2.5 mRNA and protein expression levels were decreased in the rat HF model ( $\mathrm{n}=6$ animals/group). * $\mathrm{P}<0.05$. MI, myocardial infarction; Nkx2.5, homeobox protein Nxk-2.5; LA, left atrium; LVEDD, left ventricular end-diastolic dimension; LVESD, left ventricular end-systolic dimension; LVFS, left ventricular fractional shortening; LVEF, left ventricular ejection fraction.

\section{Results}

Nkx2.5 expression is impaired in a myocardial infarctionheart failure rat model. Heart failure is one of the most common causes of AF. A previous study has demonstrated that MI-induced heart failure leads to atrial remodeling and promotes AF (10). In the present study, the size of left ventricle was enlarged and the LV contraction function was decreased 4 weeks after LAD ligation. To assess whether AF was associated with changes in $\mathrm{Nkx} 2.5$ expression, $\mathrm{Nkx} 2.5$ mRNA and protein levels were measured in the rats LA tissues. Nkx2.5 mRNA and protein expression levels were decreased in the LA of the AF model rats when compared with the sham rats (Fig. 1).

Optimum MOI value of transfection and Nkx2.5 gene silencing efficiency in HL-1 cells. HL-1 cells were transfected with GFP and the Nkx2.5 gene at a range of MOI values. HL-1 cells exhibited green fluorescence following viral transfection. As MOI increased to 20, the transfection efficiency was concomitantly increased. At MOI 20, the transfection efficiency was $>80 \%$ (Fig. 2). The optimum MOI value of transfection was 20 and was used for all subsequent analyses in the present study. Nkx2.5 mRNA and protein levels were significantly decreased following Nkx2.5 interference $48 \mathrm{~h}$ following transfection (Fig. 3).

Effect of Nkx2.5 silencing on the expression of HCN4 and $C \times 40$. To further investigate the underling effect of $\mathrm{Nkx} 2.5$ on electrophysiology, the mRNA and protein expression levels of HCN4 and Cx40 were analyzed. As presented in Fig. 4, HCN4 expression increased significantly following Nkx2.5 silencing; by contrast, $\mathrm{Cx} 40$ expression was severely decreased.

Effect of Nkx2.5 silencing on the expression of calcium handling and Wnt11 signaling. To investigate the regulatory role of $\mathrm{Nkx} 2.5$ on the expression of calcium handling proteins, the present study assessed whether Nkx2.5 silencing impaired calcium handling protein expression levels. Western blot analysis revealed significantly decreased protein expression levels of SERCA2a, $\mathrm{Ca}_{\mathrm{v}} 1.2$ and P-PLB, whereas the phosphorylated RyR2 expression level was increased. No change in total RyR and total PLB expression levels was exhibited in the sh-Nkx2.5 HL-1 cells. Wnt11 expression was decreased following transfection with $\mathrm{Nkx} 2.5$ (Fig. 5).

\section{Discussion}

$\mathrm{Nkx} 2.5$ is a homeobox transcription factor that serves an important role in embryogenesis. A recent study found that GWAS identified risk variants near Nkx2.5, which are associated with $\mathrm{AF}$, and it has been suggested that $\mathrm{Nkx} 2.5$ may be a causative connection (4); however, it did not provide experimental results regarding the regulation of $\mathrm{Nkx} 2.5$ and its association with electrophysiology.

The results of the present study demonstrated that Nkx2.5 mRNA and protein expression levels were decreased in the AF rat model, suggesting a potential association between $\mathrm{Nkx} 2.5$ loss of function and atrial electrophysiology substrates. Specifically, in HL-1 cells, Nkx2.5 silencing led to ion channel remodeling. HCN 4 channels, the pore-forming $\alpha$-subunits of funny channels, have been demonstrated to be closely associated with spontaneous activity (11). The increased expression of HCN4 in the atrial and pulmonary vein, and the decreased expression in the sinoatrial node, were revealed to be associated with the onset and maintenance of $\mathrm{AF}$ (12). In the present study, $\mathrm{Nkx} 2.5$ silencing increased HCN4 mRNA and protein expression levels in HL-1 cells, which may generate abnormal automaticity and pacemaker activity in the atrium in vivo. In patients with $\mathrm{AF}$, a variety of mutations in the coding region of $\mathrm{Cx} 40$ have been previously identified $(13,14)$. In a Cx40 loss of function mouse model, atrial conduction velocity was decreased with the increased incidence of AF episodes (15). In the present study, Nkx2.5 silencing was demonstrated to downregulate $\mathrm{Cx} 40$. 
A

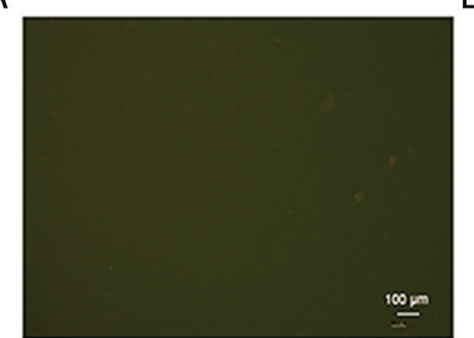

D

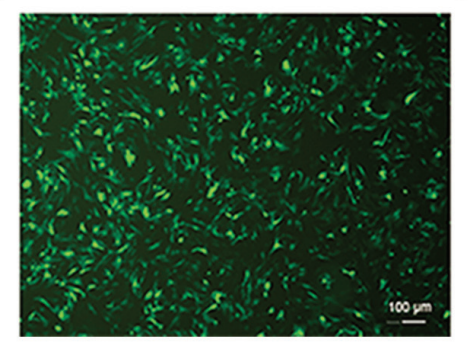

B

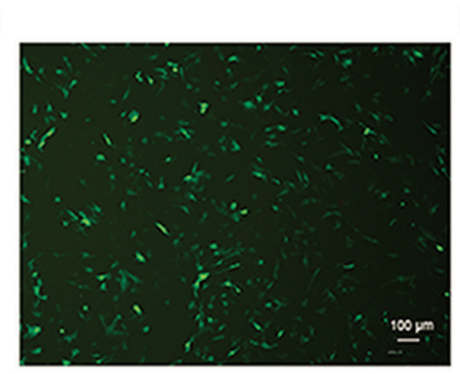

E

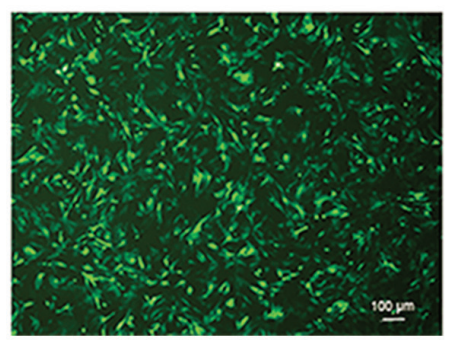

C

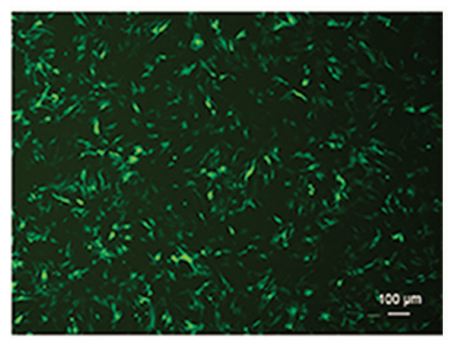

F

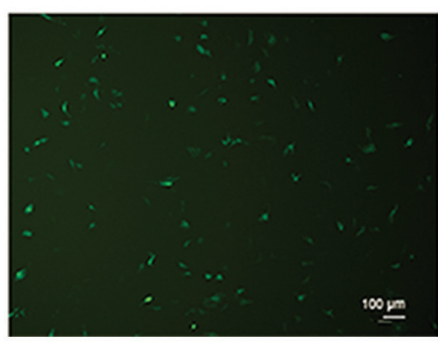

Figure 2. HL-1 cells observed under a fluorescence microscope at different MOI values at magnification, x100. (A) MOI=0. (B) MOI=2. (C) MOI=5. (D) MOI=10. (E) MOI=20. (F) MOI=50. MOI, multiplicity of infection.

A

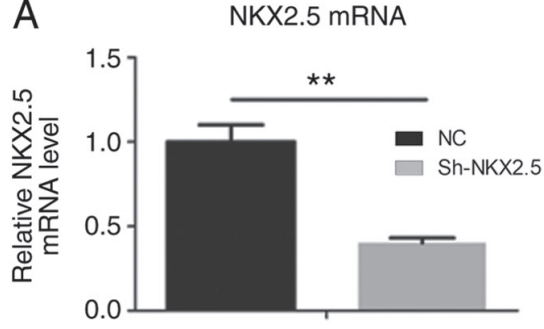

B

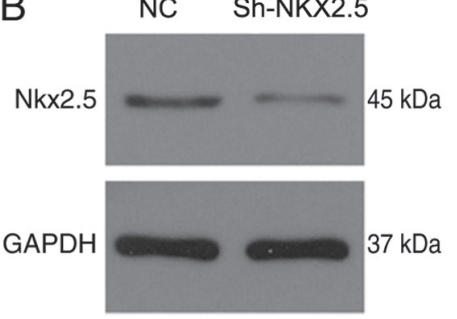

NKX2.5 protein



Figure 3. Gene silencing efficiency of Nkx2.5 in HL-1 cells. (A) Reverse transcription-quantitative polymerase chain reaction analysis revealed that HL-1 cells transfected with adenoviral vectors carrying specific Nkx2.5-shRNA exhibited a decreased level of Nkx2.5 mRNA expression (n=5 animals/group). (B) Western blot analysis demonstrated the same trend ( $\mathrm{n}=5$ animals/group). ${ }^{*} \mathrm{P}<0.05$ and ${ }^{* *} \mathrm{P}<0.01$. Nkx2.5, homeobox protein Nxk-2.5; shRNA, short hairpin RNA; NC, negative control.

A

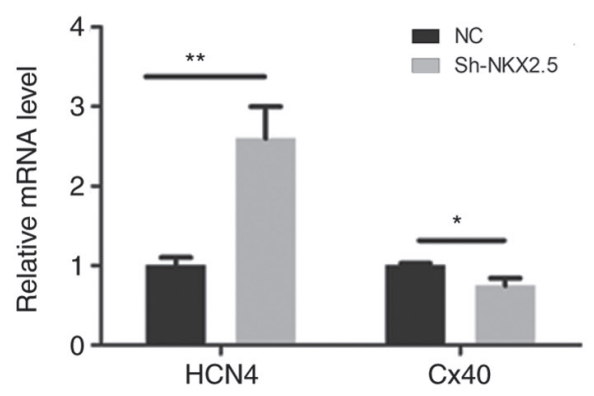

B

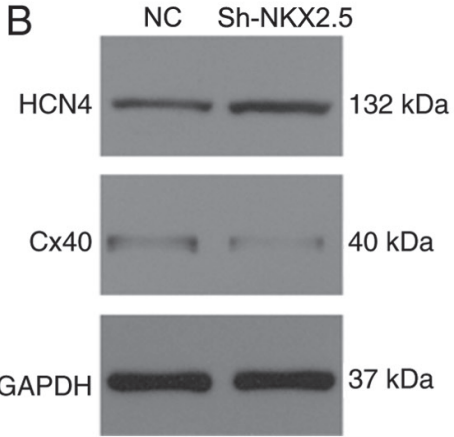

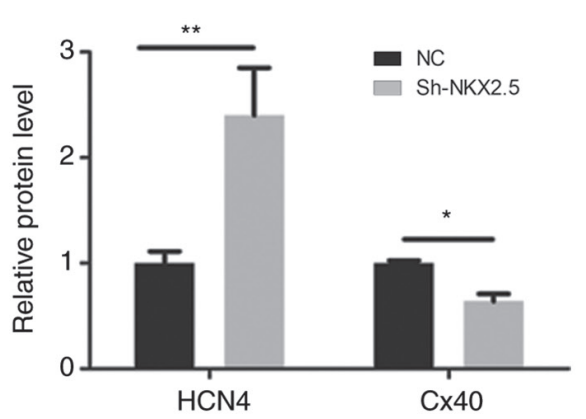

Figure 4. HCN4 and Cx40 expression levels following Nkx2.5 knockdown. (A) Reverse transcription-quantitative polymerase chain reaction data indicated that the HCN4 mRNA expression levels were increased following silencing of Nkx2.5. The opposite response was observed in the Cx40 mRNA expression levels ( $\mathrm{n}=5$ animals/group). (B) The western blot analysis data demonstrated the same pattern of expression in HCN4 and Cx 40 protein levels. " $\mathrm{P}<0.05$ and ${ }^{* *} \mathrm{P}<0.01$. HCN4, potassium/sodium hyperpolarization-activated cyclic nucleotide-gated channel 4; Cx40, gap junction alpha-5 protein; Nkx2.5, homeobox protein Nxk-2.5; shRNA, short hairpin RNA; NC, negative control.

Abnormal calcium handling has been indicated to contribute to AF. In the present study, phosphorylated RyR at S2814 was increased following Nkx2.5 silencing. RyR2 is the primary SR calcium release channel located in cardiomyocytes and it has been revealed that increased phosphorylation of RyR2 increases the incidence of arrhythmia due to diastolic SR calcium leakage (16). SERCA2a is responsible for pumping calcium back to the SR during diastole to avoid an increase in intracytoplasmic calcium concentration, which may increase the sodium-calcium exchange and triggered activity. PLB has 
A

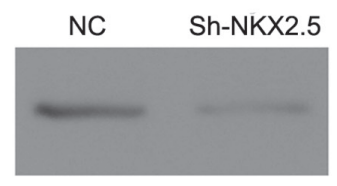

P2814-RyR2

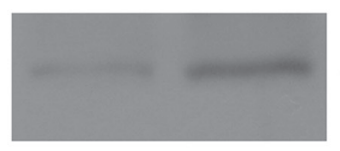

RyR

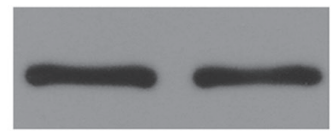

$565 \mathrm{kDa}$

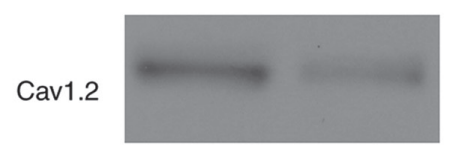

$565 \mathrm{kDa}$

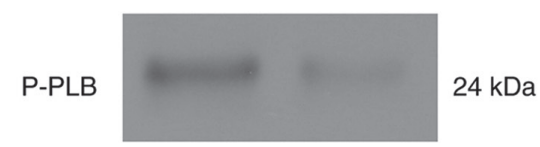

PLB

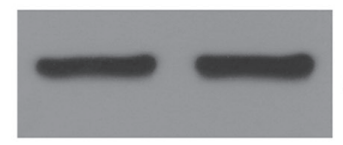

$24 \mathrm{kDa}$

Wnt11



$37 \mathrm{kDa}$

GAPDH

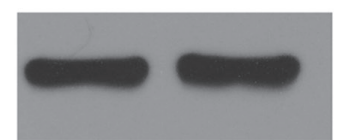

B



C



Figure 5. Nkx2.5 downregulation disrupted the expression of calcium handling proteins and Wnt11 signaling. (A) Representative western blot analysis blots and summary analysis of (B) SERCA2a, Cav1.2, Wnt11 and (C) p-RyR2/RyR, p-PLB/PLB protein expression levels. (n=5 animals/group). *P<0.05. Nkx2.5, homeobox protein Nxk-2.5; SERCA2a, sarcoplasmic reticulum Ca2+-ATPase; PS2814-RyR2, ryanodine receptor 2 phosphorylated at serine 2814; Cav1.2, voltage-dependent L-type calcium channel subunit alpha-1C; PLB, total phospholamban; P-PLB, phosphorylated phospholamban at Thr17; Wnt11, protein Wnt-11; sh, short hairpin RNA; NC, negative control..

been demonstrated to bind to SERCA2a and inhibit its activity; following phosphorylation, this inhibition of SERCA2a is lost (17). In the present study, SECA2a and P-PLB expression was impaired during $\mathrm{Nkx} 2.5$ silencing. These data support the assumption that $\mathrm{Nkx} 2.5$ gene silencing may lead to electrical remodeling, which may be the mechanism by which $\mathrm{Nkx} 2.5$ variation is associated with the onset of arrhythmia events.

The Wnt11 signaling pathway has been previously demonstrated to be crucial for myocardial cell differentiation $(18,19)$ and is in parallel with $\mathrm{Nkx} 2.5$ expression in differentiating embryoid bodies (20). Wnt11 signaling is important in ventricle organization. The expression of ventricular genes and the ventricular structure are dysregulated during Wnt11 downregulation (21). Furthermore, the Wnt11 signaling pathway is a critical regulator of calcium handling $(8,22)$. In the present study, the association between $\mathrm{Nkx} 2.5$ and Wnt11 was assessed. The results revealed that Wnt11 protein expression was significantly decreased following Nkx2.5 silencing. These results provide evidence for a potential association between Nkx2.5 and the Wnt11 signaling pathway.

In conclusion, to the best of our knowledge, the present study revealed for the first time that $\mathrm{Nkx} 2.5$ expression is significantly decreased in a HF rat model. The present study provides evidence that impaired $\mathrm{Nk} 2.5$ function is associated with calcium homeostasis and $\mathrm{Cx} 40$ and HCN4 expression levels, which leads to atrial electric remodeling. This is associated with arrhythmogenesis, which may act via the Wnt11 signaling pathway.

Although Nkx2.5 gene silencing was demonstrated to be associated with the alteration of calcium handling proteins, HCN4, Cx40 and Wnt11 expression levels, further in vivo and in vitro experiments assessing the effect of $\mathrm{Nkx} 2.5$ on atrial electrophysiology, including action potential duration, effective refractory period and calcium leak, are required. Further experiments examining $\mathrm{Nkx} 2.5$ overexpression in an $\mathrm{AF}$ animal model are required to explore the role of NKX2.5 in the pathogenesis of AF.

\section{Acknowledgements}

Not applicable.

\section{Funding}

The present study was supported The Science and Technology Foundation of Guizhou Province [grant no., LH-(2017)-7199]. 


\section{Availability of data and materials}

The datasets used and/or analyzed during the current study are available from the corresponding author on reasonable request.

\section{Authors contributions}

WZ conceived, designed and supervised the present study. JC and SX developed the methodology, reviewed the manuscript and analyzed and interpreted the data. WL, LRW, LW and YL were responsible for statistical analysis and data interpretation. All authors read and approved the final manuscript.

\section{Ethical approval and consent to participate}

All experimental protocols were approved by The Experimental Animal Care and Institutional Animal Ethical Committee of Guizhou Medical University.

\section{Patient consent for publication}

Not applicable.

\section{Competing interests}

The authors declare that they have no competing interests.

\section{References}

1. Wilke T, Groth A, Mueller S, Pfannkuche M, Verheyen F, Linder R, Maywald U, Bauersachs R and Breithardt G: Incidence and prevalence of atrial fibrillation: An analysis based on 8.3 million patients. Europace 15: 486-493, 2013.

2. Andrade J, Khairy P, Dobrev D and Nattel S: The clinical profile and pathophysiology of atrial fibrillation: Relationships among clinical features, epidemiology, and mechanisms. Circ Res 114: 1453-1468, 2014.

3. Ye W, Wang J, Song Y, Yu D, Sun C, Liu C, Chen F, Zhang Y, Wang F, Harvey RP, et al: A common Shox2-Nkx2-5 antagonistic mechanism primes the pacemaker cell fate in the pulmonary vein myocardium and sinoatrial node. Development 142: 2521-2532, 2015.

4. Nielsen JB, Thorolfsdottir RB, Fritsche LG, Zhou W, Skov MW, Graham SE, Herron TJ, McCarthy S, Schmidt EM, Sveinbjornsson $\mathrm{G}$, et al: Biobank-driven genomic discovery yields new insight into atrial fibrillation biology. Nat Genet 50: $1234-1239,2018$.

5. Huang RT, Xue S, Xu YJ, Zhou M and Yang YQ: A novel NKX2.5 loss-of-function mutation responsible for familial atrial fibrillation. Int J Mol Med 31: 1119-1126, 2013.

6. National Institutes of Health. Guide for the Care and Use of Laboratory Animals. 8th edition. National Academies Press, Washington, pp86-23, 2011.

7. Claycomb WC, Lanson NA Jr, Stallworth BS, Egeland DB, Delcarpio JB, Bahinski A and Izzo NJ Jr: HL-1 cells: A cardiac muscle cell line that contracts and retains phenotypic characteristics of the adult cardiomyocyte. Proc Natl Acad Sci USA 95: 2979-2984, 1998.
8. Lozano-Velasco E, Hernandez-Torres F, Daimi H, Serra SA, Herraiz A, Hove-Madsen L, Aránega A and Franco D: Pitx2 impairs calcium handling in a dose-dependent manner by modulating Wnt signalling. Cardiovasc Res 109: 55-66, 2016.

9. Livak KJ and Schmittgen TD: Analysis of relative gene expression data using real time quantitative PCR and the 2(-Delta Delta C(T)) method. Methods 25: 402 408, 2001.

10. Cardin S, Guasch E, Luo X, Naud P, Le Quang K, Shi Y, Tardif JC, Comtois $\mathrm{P}$ and Nattel S: Role for MicroRNA-21 in atrial profibrillatory fibrotic remodeling associated with experimental postinfarction heart failure. Circ Arrhythm Electrophysiol 5: 1027-1035, 2012

11. DiFrancesco D: HCN4, sinus bradycardia and atrial fibrillation. Arrhythm Electrophysiol Rev 4: 9-13, 2015.

12. Li YD, Hong YF, Zhang Y, Zhou XH, Ji YT, Li HL, Hu GJ, Li JX, Sun L, Zhang JH, et al: Association between reversal in the expression of hyperpolarization-activated cyclic nucleotide-gated $(\mathrm{HCN})$ channel and age-related atrial fibrillation. Med Sci Monit 20: 2292-2297, 2014

13. Yang YQ, Liu X, Zhang XL, Wang XH, Tan HW, Shi HF, Jiang WF and Fang WY: Novel connexin40 missense mutations in patients with familial atrial fibrillation. Europace 12: 1421-1427, 2010.

14. Sun Y, Yang YQ, Gong XQ, Wang XH, Li RG, Tan HW, Liu X, Fang WY and Bai D: Novel germline GJA5/connexin40 mutations associated with lone atrial fibrillation impair gap junctional intercellular communication. Hum Mutat 34: 603-609, 2013.

15. Lübkemeier I, Andrié R, Lickfett L, Bosen F, Stöckigt F, Dobrowolski R, Draffehn AM, Fregeac J, Schultze JL, Bukauskas FF, et al: The Connexin40A96S mutation from a patient with atrial fibrillation causes decreased atrial conduction velocities and sustained episodes of induced atrial fibrillation in mice. J Mol Cell Cardiol 65: 19-32, 2013.

16. Houser SR: Role of RyR2 phosphorylation in heart failure and arrhythmias: Protein kinase A-mediated hyperphosphorylation of the ryanodine receptor at serine 2808 does not alter cardiac contractility or cause heart failure and arrhythmias. Circ Res 114: 1320-1327; discussion 1327, 2014.

17. Samuel TJ, Rosenberry RP, Lee S and Pan Z: Correcting calcium dysregulation in chronic heart failure using SERCA2a gene therapy. Int J Mol Sci 19, 2018.

18. Bisson JA, Mills B, Paul Helt JC, Zwaka TP and Cohen ED: Wnt5a and Wnt11 inhibit the canonical Wnt pathway and promote cardiac progenitor development via the Caspase-dependent degradation of AKT. Dev Biol 398: 80-96, 2015.

19. Cohen ED, Miller MF, Wang Z, Moon RT and Morrisey EE: Wnt5a and Wnt11 are essential for second heart field progenitor development. Development 139: 1931-1940, 2012.

20. Terami H, Hidaka K, Katsumata T, Iio A and Morisaki T: Wnt11 facilitates embryonic stem cell differentiation to $\mathrm{Nkx} 2.5$-positive cardiomyocytes. Biochem Biophys Res Commun 325: 968-975, 2004.

21. Nagy II, Railo A, Rapila R, Hast T, Sormunen R, Tavi P, Räsänen J and Vainio SJ: Wnt-11 signalling controls ventricular myocardium development by patterning $\mathrm{N}$-cadherin and beta-catenin expression. Cardiovasc Res 85: 100-109, 2010.

22. Panáková D, Werdich AA and Macrae CA: Wnt11 patterns a myocardial electrical gradient through regulation of the L-type $\mathrm{Ca}(2+)$ channel. Nature 466: 874-878, 2010 .

(i) (9) This work is licensed under a Creative Commons Attribution-NonCommercial-NoDerivatives 4.0 International (CC BY-NC-ND 4.0) License. 